DOI: https://doi.org/10.24867/11BE26Marinkovic

\title{
PROCES HARMONIZACIJE DNEVNIH PLANOVA RADA EES U OKVIRU EVROPSKE INTERKONEKCIJE
}

\section{DAY AHEAD SCHEDULING PROCESS WITHIN EUROPEAN INTERCONNECTION}

\author{
Sanja Marinković, Fakultet tehničkih nauka, Novi Sad
}

\begin{abstract}
Oblast - ELEKTROTEHNIKA I RAČUNARSTVO
Kratak sadržaj - U radu je predstavljena analiza funkcionisanja i razvoj sistema za prijavu dnevnih planova rada (ESS - ENTSO-E Scheduling System). Pored detaljnog opisa načina kreiranja i značaja dnevnih planova rada, $u$ radu je predstavljen $i$ razvoj tržišta električne energije, kako u Evropi, tako i u Srbiji. Rad se bavi i načinom na koji se sprovode aukcije za raspodelu prekograničnih prenosnih kapaciteta, procesom kreiranja izveštaja, i dokumenata koji se razmenjuju na Verifikacionoj platformi, u cilju uspešno završenog procesa dan unapred.
\end{abstract}

Ključne reči: ENTSO-E, scheduling, dnevni plan rada, tržište, aukcije, kapacitet, Verifikaciona platforma, izveštaj

Abstract - The paper presents an analysis of the functioning and development of a system for day ahead trading (ESS - ENTSO-E Scheduling system). In addition to a detailed description of the way of creating and the importance of day ahead schedules, the paper also presents the development of the electricity market, both in Europe and in Serbia. The paper also deals with the way in which auctions for the allocation of cross-border transmission capacities are conducted, the process of creating reports, and the documents that are exchanged on the Verification Platform, in order to successfully complete the Day Ahead process.

Keywords: ENTSO-E, scheduling, day ahead schedules, market, auctions, capacity, Verification Platform, report

\section{UVOD}

Krajem prošlog veka na tržištu električne energije postojao je monopol, čija je posledica bila neprihvatljivo velika cena električne energije koju je plaćao kupac. Cilj unapređenja tržišta je ukinuti monopol, tj. stvoriti konkurentno tržište.

Liberalizacijom tržišta i uvođenjem konkurentnog tržišta je uslovilo potrebu da se donesu jasna i standardizovana pravila u cilju efikasnog fukncionisanja tržišta električne energije. Pravila koja su doprinela tome jesu Pravila o radu prenosnog sistema i Pravila o radu tržišta električne energije.

\footnotetext{
NAPOMENA:

Ovaj rad proistekao je iz master rada čiji mentor je bio dr Nenad Katić.
}

Radi sigurnijeg rada regionalne grupe Kontinentalna Evropa (RGCE - Regional Group Continental Europe), i stvaranja pogodnosti za komercijalnu trgovinu električnom energijom, potrebno je unapred planirati sve prekogranične razmene po interkonektivnim dalekovodima između operatora prenosnih sistema.

U skladu sa promenom tržišta i donetim pravilima, dolazi i do razvoja sistema za prijavu dnevnih planova rada (ESS - ENTSO-E Scheduling System), čije je funkcionisanje predmet ovog rada.

Ovaj rad će proći kroz sve potrebne segmente za izradu dnevnih planova rada i procesom harmonizacije dnevnih planova rada, kao i kroz nastanak i razvoj tržišta električne energije u Evropi i Srbiji. Baviće se načinom na koji se sprovode aukcije za raspodelu prekograničnih prenosnih kapaciteta, izveštajima koji se kreiraju nakon završetka harmonizacije dnevnih planova rada, i motivacijom za uvođenje Verifikacione platforme i njenim načinom rada.

\section{TRŽIŠTE ELEKTRIČNE ENERGIJE}

Prilikom trgovanja na tržištu, kupac i prodavac moraju da dogovore količinu i kvalitet robe, cenu, datum isporuke, način i mesto isporuke, način plaćanja, kao i eventualne druge uslove vezane za posao. Način na koji kupci i prodavci rešavaju ove stvari definišu tipove tržišta. Tipovi tržišta mogu biti:

1) Bilateralno tržište: kupac i prodavac direktno se međusobno dogovaraju oko svih elemenata trgovine, koji ostaju poslovna tajna između strana.

2) Berza ili upravljano tržište: operator organizuje mesto za trgovanje pod određenim pravilima pristupa (licenca, minimalna količina trgovanja, finansijski depozit), cena i količine su javni, dok identitet učesnika nije poznat.

3) Centralno tržište: Cenu određuje berza i prodavci su u obavezi da prihvate cenu u transakcijama.

4) Balansno tržište: Operator prenosnog sistema ima ključnu ulogu u liberalizaciji tržišta sistemskih (pomoćnih) usluga, čija je cena regulisana, i omogućavanju postojanja većeg broja snabdevača za pomoćne usluge.

Početak jednog od najvećeg projekta evropskih integracija započet je 23.05.1951. godine. Uloga ovog projekta je bila da se doprinese razvoju ekonomije kroz efikasnije korišćenje energetskih resursa, koje je omogućavalo međusobno povezivanje elektroenergetskih sistema. Sa što većom povezanošću Zapadne Evrope, osnovano je UCPTE (Union for the Co-ordination of Production and 
Transmission of Electricity) - Udruženje za koordinaciju proizvodnje i prenosa električne energije od strane tada vertikalno integrisanih elektroenergetskih kompanija Austrije, Zapadne Nemačke, Belgije, Francuske, Italije, Holandije i Švajcarske. Mreže su se širile, te se 1987. godine članovima osnivača dodatno pridružile Španija, Jugoslavija i Portugal.

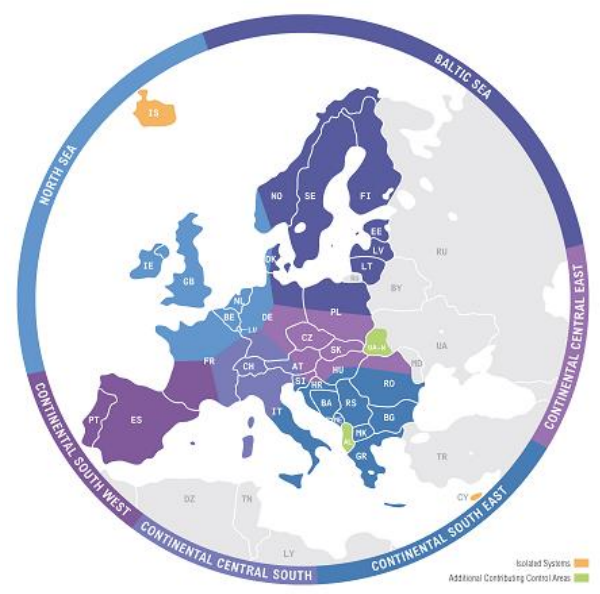

Slika 1. UCPTE mapa sa pridruženim članovima [1]

Devedesetih godina dolazi do razdvajanja proizvodnih, prenosnih i distributivnih usluga u cilju obezbeđivanja fer i nediskriminatornog pristupa mreži svim korisnicima, a samim tim i uspostavljanje konkurentnog tržišta. To je dovelo do toga da 1999. godine UCTPE promeni svoj naziv u UCTE (Union for the Coordination of Transmission of Electricity) - Unija za koordinaciju prenosa električne energije. Ova grupa je bila usresređena na postavljanje tehničkih pravila. Sva postojeća pravila bila su zamenjena UCTE Operativnim priručnicima - UCTE Operation Handbook, koji sadrže anekse kojim se opisuje princip rada i pravila za operatore prenosnih sistema $u$ kontinentalnoj Evropi. Cilj ovih priručnika je da pruže podršku tehničkom upravljanju povezanom mrežom sinhronih oblasti.

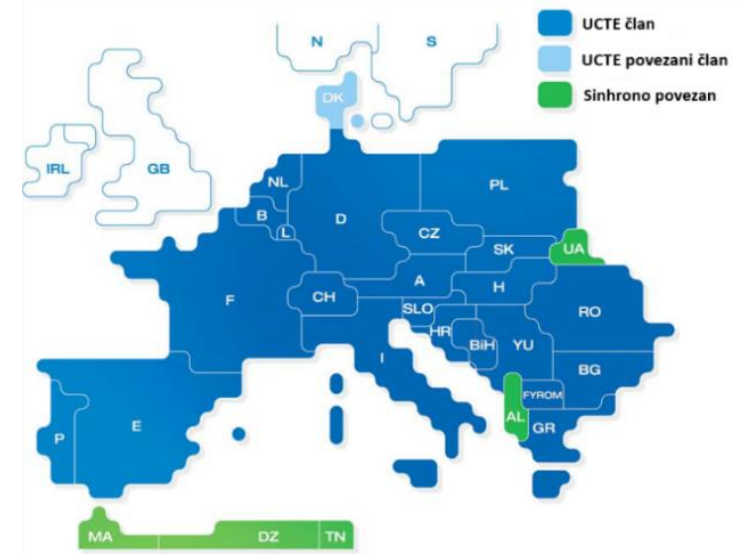

Slika 2. UCTE mapa [1]

Spajanjem četiri institucije (NORDEL, UKTSOA, ATSOI, BALTSO) 1. jula 1999. godine osnovana je ETSO (European Transmission System Operators) zajednica, tj. Asocijacija Operatora prenosnih sistema Evrope, sa ciljem da pouzdanost sistema treba da bude najviši prioritet $u$ postojećem sinhronom sistemu kao stub za panevropske integracije i dalji razvoj panevropskog tržišta električne energije.
ENTSO, nakon 10 godina rada, prebacuje svoj rad u trenutnu strukturu ENTSO-E (European Network of Transmission System Operators for Electricity) - Asocijacija evropskih operatora prenosnih sistema za električnu energiju i dobija zakonske mandate trećim paketom EU. Novonastalu grupu čine 42 operatora prenosnog sistema (TSO) iz 35 zemalja širom sveta, čiji je primarni zadatak da nadgleda efikasnost mreže na regionalnom nivou, a posebno se insistira na saradnji članova ENTSO-E. ENTSO-E je podeljen na pet regionalnih grupa, koje su zasnovane na sinhronim zonama: Kontinentalna Evropa, nordijska, baltička, Velika Britanija i Irska-Severna Irska i dve dobrovoljne regionalne grupe (u severnoj Evropi i izolovani sistemi) [1].

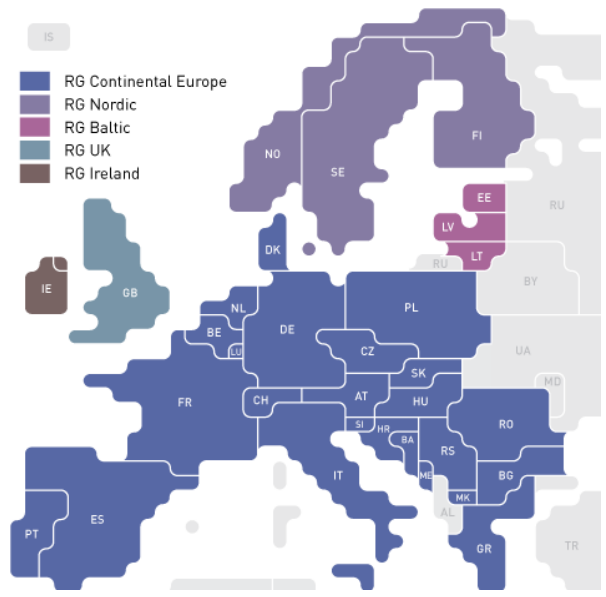

Slika 3. ENTSO-E interkonekcija [1]

Reforma energetskog sektora u Srbiji započeta je 2004. godine usvajanjem prvog Zakona o energetici. Zakonom se u velikoj meri poboljšava ambijent za investicije u energetski sektor, kao i veća zaštita kupaca. Sa ovim zakonom je osnovana Agencija za energetiku Republike Srbije (AERS), kao nezavisno regulatorno telo za obavljanje poslova na unapređivanju i usmeravanju razvoja tržišta električne energije na principa nediskriminacije i efikasne konkurencije, pružanju primene propisa i pravila za rad energetskih sistema.

Sa formiranjem AERS, vrši se razdvajanje operatora prenosnog i distributivnog sistema električne energije na:

1) Javno preduzeće „Elektroprivreda Srbije“ (JP EPS), vrši delatnost proizvodnje, trgovine i distribucije električne energije,

2) „Elektromreža Srbije“ AD Beograd (EMS AD), bavi se delatnošću prenosa električne energije i upravljanjem prenosnim sistemom.

EMS AD je operator prenosnog sistema i tržišta električne energije i organizator berze električne energije u Srbiji. Prva licenca za trgovinu električnom energijom doneta je 16. juna 2006. godine od strane Agencije za energetiku Republike Srbije.

Uvođenje eksplicitnih aukcija 2007. godine se smatra prvim korakom ka otvaranju tržišta električne energije.

Potpunim otvaranjem tržišta električne energije i prirodnog gasa, stvorila se mogućnost pojave novih energetskih subjekata na tržištu, pre svega snabdevača, čime se postiže konkurentnost na tržištu, dok se kupcima omogućuje slobodan izbor snabdevača. 


\section{AUKCIJE ZA RASPODELU PREKOGRANIČNIH PRENOSNIH KAPACITETA}

Operator prenosnog sistema, uz saglasnost Agencije za energetiku, donosi Pravila za raspodelu prekograničnih prenosnih kapaciteta, čime se uređuju postupak i način raspodele prava na korišćenje prekograničnih prenosnih elektroenergetskih kapaciteta.

Tipovi kapaciteta se mogu podeliti u dve velike grupe:

1) Dugoročni (long-term): godišnji, mesečni, nedeljni i total,

2) Kratkoročni (short-term): dnevni i unutardnevni.

Postoje dva načina organizovanja aukcija, tj. postoje dve vrste aukcija:

1) Joint aukcije: Mađarska, Rumunija, Bugarska, Severna Makedonija, Crna Gora, Hrvatska, Bosna i Hercegovina

2) Split aukcije: Albanija [2]

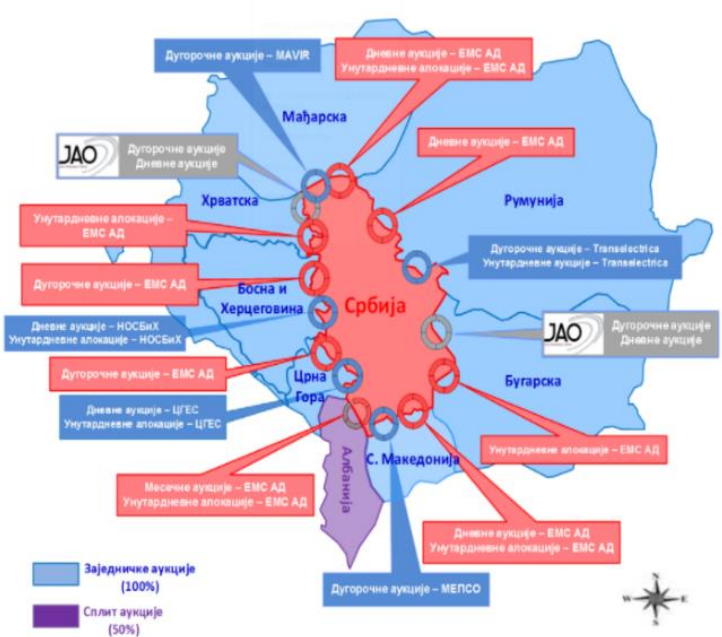

Slika 5. Načini sprovođenja aukcija [2]

\section{PROCES HARMONIZACIJE DNEVNIH PLANOVA RADA}

Scheduling proces podrazumeva proces prijave dnevnih planova rada balansnih grupa na vremenskom horizontu dan unapred i unutar dana. Učesnici prijavljuju planove rada u skladu sa Pravilima o radu prenosnog sistema i Pravilima o radu tržišta električne energije.

Pravo pristupa Scheduling sistemu se stiče dobijanjem licence od Agencije za energetiku Republike Srbije, dobijanjem EIC koda, potpisivanjem ugovora o Balansnoj odgovornosti sa EMS AD i dobijanjem tokena za pristup Scheduling sistemu.

Scheduling sistem koji operator prenosnog sistema Srbije, tj. EMS AD koristi je Novita. Sistem podržava odvojene long-term i short-term nominacione cikluse. Svaki nominacioni ciklus se završava jednim ili više harmonizacionim ciklusima.

Učesnik na tržištu može da prijavljuje u Scheduling sistem:

1) Plan razmene za dan $D$ u danu D-1,

2) Plan ukupne proizvodnje za dan D u danu D-1,

3) Plan ukupne potrošnje za dan D u danu D-1.
Scheduling sistem šalje trgovcima sledeće poruke:

1) ACK - Acknowledgment (potvrda o prijemu i verifikaciji),

2) CNF - Confirmation Report (izveštaj o prihvatanju dostavljenih dnevnih planova rada),

3) ANO - Anomaly Report (izveštaj o nepravilnosti dostavljenih planova rada).

Kapija za prijavljivanje short-term kapaciteta se u sistemu naziva Short Term $R D$ i otvara se na svim granicama u danu D-1 u 09:30h, a zatvara se za granice na kojima se obavljaju joint aukcije u 11:00h (D-1), odnosno u 12:00h (D-1) za granice na kojima se obavljaju split aukcije.

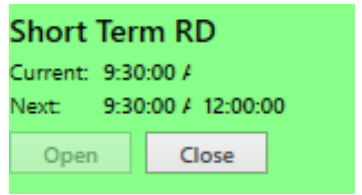

Slika 6. Kapija za prijavljivanje short-term kapaciteta [3] Kapija za prijavljivanje long-term kapaciteta se u sistemu zove Long Term RD i otvorena je na svim granicama do $16 \mathrm{~h}$ u D-2 za dan D.

Long Term RD
Current: 12:10:00
\begin{tabular}{ll} 
Next: & $12: 10: 00,4: 00: 00 \mathrm{~F}$ \\
\hline Open & Close \\
\hline
\end{tabular}

Slika 7. Kapija za prijavljivanje long-term kapaciteta [3] U periodu od 00:10h (D-7) do 08:00h (D-1) otvorena je, na granicama na kojima se sprovode joint aukcije, kapija za prijavljivanje planova rada po dugoročnim kapacitetima, koja se u sistemu naziva Long Term Nomination.

Long Term Nomination
Current: $12: 10: 00$,
\begin{tabular}{cc} 
Next: $12: 10: 00,2: 30: 00 \mathrm{~F}$ \\
\hline Open & Close \\
\hline
\end{tabular}

Slika 8. Kapija za prijavljivanje planova rada po longterm kapacitetima [3]

U periodu od 10:00h (D-1) do 14:30h (D-1) otvorena je i kapija za prijavljivanje planova po short-term kapacitetima. Kapija za prijavljivanje planova po long-term kapacitetima na Albaniji je otvorena do 14:30h (D-1) zato što se usaglašavanje dnevnih planova rada vrši u nominacionom ciklusu po short-term kapacitetima.

Short Term Nomination
Current: 10:00:00
\begin{tabular}{cc} 
Next $\quad$ 10:00:00 2:30:00 F \\
\hline Open $\quad$ Close
\end{tabular}

Slika 9. Kapija za prijavljivanje planova rada po longterm kapacitetima [3]

Dokumenti koji se razmenjuju u nominacionim ciklusima su:

1) CAS - plan razmene između dve regulacione oblasti (sadrži sve transakcije svih trgovaca u određenoj oblasti)

2) $\mathrm{ACK}$,

3) $\mathrm{CNF}$

4) CAX - program razmene članice kontrolnog bloka koji sadrži sve netovane razmene po svakoj granici regulacione oblasti. 
Na početku svakog nominacionog ciklusa (u 08:00h (D-1) i 14:30h (D-1)) sistem Novita kreira lokalni CAS, koji se šalje susednom operatoru, i nakon dobijanja pozitivnog Acknowledgment-a, nastavlja se dalji proces harmonizacije dnevnih planova rada, odnosno usaglašavanja vrednosti našeg i susednog CAS fajla. U slučaju da postoji neusaglašenost između razmenjenih planova razmene, inženjer korišćenjem Scheduling sistema utvrđuje koji je učesnik na tržištu odgovoran za tu razliku, i kontaktira je da bi utvrdio da li su ispravni podaci u našem ili u sistemu susednog operatora. Tom učesniku se prosleđuje token za izmenu prijavljenog dnevnog plana.

Nakon uspešno završenog nominacionog ciklusa po shortterm kapacitetima, koji počinje u 14:30h (D-1), inženjer kreira CAX. EMS AD, kao i operator SMM kontrolnog bloka, proverava da li je Scheduling sistem primio CAX od članica kontrolnog bloka (Crna Gora (CGES) i Severna Makedonija (MEPSO)).

Proces harmonizacije je isti [4].

\section{REZULTATI}

Proces harmonizacije podrazumeva proveru usklađenosti dnevnih planova rada sa Pravilima o radu prenosnog sistema i Pravilima o radu tržišta električne energije u pogledu izbalansiranosti plana i prijave internih blokova razmene, postizanje identičnih vrednosti planova razmene sa susednim operatorom prenosnog sistema za svaki blok prekogranične razmene i program razmene unutar kontrolnog bloka.

\section{IZVEŠTAJI DNEVNOG PLANA RADA}

Nakon zatvaranja procesa dan unapred, inženjer kreira dnevnih plan rada prenosnog sistema koristeći makro. Sam proces je automatizovan i nakon kreiranja izveštaja, potrebno je uporediti validnost podataka dnevnih planova rada sa Scheduling sistemom. Ovaj izveštaj je, pre svega, potreban za primopredaju smene Regionalnog dispečerskog centra.

\section{VERIFIKACIONA PLATFORMA}

Verifikaciona platforma predstavlja nov način razmene podataka u ENTSO-E regionalnoj grupi Kontinentalna Evropa, koja objedinjuje programe rada evropskih operatora sistema.

Cilj platforme je usavršiti način komunikacije sa operatorima sistema i regulacionih blokova i omogućiti lakši pristup neophodnim podacima. Nemački i Švajcarski operatori Amprion i Swissgrid su odgovorni za prijem svih programa razmene u ENTSO-E regionalnoj grupi Kontinentalna Evropa.

Motivacija za uvođenje Verifikacione platforme je napuštanje principa rada po UCTE piramidi i smanjivanje broja fajlova koji se razmenjuju. Platformom se obezbeđuju precizniji ulazni podaci za analizu sigurnosti elektroenergetskog sistema, kao i sam razvoj tržišta i tržišnih funkcija koje obuhvataju prekograničnu razmenu sekundarne i tercijarne regulacije.

Fajlovi koji se razmenjuju su svrstani u fajl SAX (Aggregated netted external schedules), koji može sadržati:
1) Komercijalne razmene $u$ dan unapred i unutardnevnom proces (MDA - Market Day ahead, MID Market Intraday),

2) Razmene operatora prenosnih sistema u dan unapred i unutardnevnom procesu (TDA - TSO Day ahead, TID - TSO Intraday), i

3) Kompenzacione programe (Compensation Program), koji pokrivaju neželjena odstupanja operatora sistema i bloka.

\section{ZAKLJUČAK}

Promene u razvoju tržišta električne energije u celoj Evropi su svakodnevne i snažne. Osnovni cilj liberalizacije tržišta električne energije je bio i jeste, podizanje efikasnosti elektroenergetskog sektora, pre svega radi povećanja konkurentnosti. Od liberalizacije tržišta električne energije očekivalo se sniženje cene električne energije, smanjivanje razlike u cenama između država, kao i mogućnost biranja snabdevača. Zacrtani ciljevi još uvek nisu postignuti, ali se nezaustavljivo ide ka njihovom ostvarenju u najvećem delu sveta.

U Srbiji, tržište za dan unapred se svakodnevno razvija. U operatoru prenosnog sistema Srbije, kada govorimo o procesu harmonizacije dnevnih planova rada očekuju se novine u radu samog sistema, u cilju automatizacije i bržeg i lakšeg zatvaranja procesa za dan unapred.

Evropska interkonekcija ENTSO-E prolazi kroz značajne i neviđeno brze promene, čime se otvaraju vrata za nove mogućnosti, što je predviđeno Četvrtim energetskim paketom, koji za cilj ima povećanje korišćenja obnovljivih izvora i smanjenje emisije štetnih gasova.

\section{LITERATURA}

[1] The 50 Year Succss Story - Evolution of a European Interconnected Grid, Publisher: Secretariat of UCTE (pristupljeno u septembru 2020.)

[2] https://ems.rs/media/uploads/2020/Prezenacije/01\%20Prezentacija\%20Alokacije\%20i\%20Garancije \%20porekla\%202020.pdf (pristupljeno u septembru 2020.)

[3] Program Novita (pristupljeno u septembru 2020.)

[4] Procedura izrade dnevnog plana rada elektroenergetskog sistema u procesu dan unapred, Jadranka Janjanin, dipl.inž.el., novembar 2015. (pristupljeno u septembru 2020.)

[5] Policy 2: Scheduling and Accounting, RG CE, 2018.

\section{Kratka biografija:}

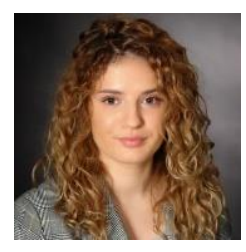

Sanja Marinković rođena je u Ćupriji 1995. god. Srednju školu Gimnazija završila je u Ćupriji 2014. godine. Diplomski rad na Fakultetu tehničkih nauka iz oblasti Elektroenergetika Elektroenergetski sistemi odbranila je 2019. godine. 